\title{
VARIAÇÃO DA DENSIDADE DE FLUXO DE SEIVA E DO POTENCIAL HÍDRICO FOLIAR NAS FACES LESTE E OESTE DA COPA DE LARANJEIRA 'VALÊNCIA'1
}

\author{
LÚCIO FLAVO LOPES VASCONCELOS², RAFAEL VASCONCELOS RIBEIRO ${ }^{3}$, \\ RICARDO FERRAZ DE OLIVEIRA ${ }^{4}$, EDUARDO CARUSO MACHADO 3
}

RESUMO - O objetivo deste trabalho foi avaliar a influência da variação diurna e sazonal dos fatores ambientais sobre a densidade de fluxo de seiva (DFS) e o potencial hídrico foliar $\left(\Psi_{\mathrm{f}}\right)$ nas faces leste e oeste da copa de laranjeiras 'Valência' em condições de sequeiro. Foram utilizadas três plantas para as avaliações, cujas linhas de plantio estavam orientadas no sentido norte-sul. As avaliações foram realizadas durante um dia, em cada época do ano: verão, outono, inverno e primavera. Os valores de potencial hídrico medidos antes do amanhecer variaram de -0,31 MPa, no dia 10-12-05, a -1,1 MPa, no dia 30-08-05, porém não houve diferença significativa entre as faces leste e oeste da copa. Já para o potencial hídrico medido às $14 \mathrm{~h} 30$, em todas as épocas avaliadas, a face oeste apresentou menores $(\mathrm{p}<0,05)$ valores que os da face leste, sendo que os mesmos variaram entre -0,95 e -1,89 MPa, verificados nos dias 10-12-05 e 30-08-05, respectivamente. A maior demanda evaporativa que se verifica no período da tarde, induz a maior déficit hídrico na face oeste da copa, independentemente da época do ano e, por consequência, maior DFS em plantas bem hidratadas sob condições de dias completamente ensolarados. Em plantas em condições de deficiência hídrica (indicada por baixos valores de $\Psi_{\mathrm{f}}$ ), a face oeste é mais sensível a essa situação, apresentando redução de DFS. Essa redução ocorre no inverno, na região de Cordeirópolis (SP).

Termos para Indexação: Citrus sinensis, método de balanço de calor, transpiração.

\section{VARIATION OF SAP FLOW DENSITY AND LEAF WATER POTENCIAL IN THE EAST AND WEST SIDE OF THE CANOPY OF 'VALENCIA' SWEET ORANGE PLANT}

\begin{abstract}
This paper aimed to study the effect of diurnal and seasonal variation of the environmental factors on the sap flow density (SFD) and leaf water potential $\left(\Psi_{1}\right)$ in the east and west side of the canopy of 'Valencia' sweet orange trees under field conditions, with no irrigation system. Were evaluated three plants, whose planting rows were north-south, oriented. The evaluations were performed during one day in each season of the year: summer, autumn, winter and spring. The values of water potential measured at predawn ranged from $-0,31 \mathrm{MPa}$, in the day $12 / 10 / 05$, to $-1,1 \mathrm{MPa}$, in the day $08 / 30 / 05$, however there was no significant difference between the east and west sides of the canopy. In the afternoon, leaves at the west side showed smaller $(\mathrm{p}<0,05)$ water potential than the ones at the east position, with values varying between $-0,95(12 / 10 / 05)$ and $-1,89 \mathrm{MPa}(08 / 30 / 05)$. The largest air evaporative demand that it is verified in the afternoon induces to a larger water deficit in the west side of the canopy independent of the time of the year and, in consequence, larger SFD in well-watered plants under conditions of completely sunny days. Under water deficit conditions (low values of $\Psi_{1}$ ), the west side of the plants is more sensible to that condition, showing reduction of SFD.
\end{abstract}

Index terms: Citrus sinensis, stem heat balance method, transpiration.

'(Trabalho 010-09). Recebido em: 05-01-09. Aceito para publicação em: 20-11-2009.

${ }^{2}$ Pesquisador Embrapa Meio-Norte, CP 01, CEP 64000-970, Teresina - PI. E-mail: lucio@cpamn.embrapa.br

${ }^{3}$ Pesquisador Científico, Instituto Agronômico, Centro de Pesquisa e Desenvolvimento em Ecofisiologia e Biofísica, CP 28, CEP 13001-970, Campinas - SP. E-mail: rafael@iac.sp.gov.br, caruso@iac.sp.gov.br.

${ }^{4}$ Prof. Dr., Escola Superior de Agricultura Luiz de Queiroz, Dept ${ }^{\circ}$ de Ciências Biológicas, CP 9, CEP 13418-900, Piracicaba - SP. E-mail: rfo@esalq.usp.br. 


\section{INTRODUÇÃO}

O estudo das relações hídricas em plantas é de fundamental importância para a compreensão da sua fisiologia. Nesse sentido, a determinação do fluxo de seiva tem merecido especial atenção por parte da comunidade científica, principalmente em pesquisas conduzidas em condições de campo. Dentre os métodos existentes para a determinação do fluxo de seiva, o método do balanço de calor caulinar apresenta uma série de vantagens em relação aos demais, dentre as quais se citam: é um método absoluto, não necessitando de calibração; exige equipamento relativamente mais simples que os demais; e é não invasivo (Marin et al., 2008). Em plantas lenhosas, tem-se mostrado eficiente na determinação do fluxo de seiva de ramos ou troncos, mesmo em plantas de grande porte (Grime \& Sinclair, 1999).

No Brasil, ao longo dos últimos onze anos, vários trabalhos foram desenvolvidos com a cultura dos citros nos quais se empregou o método de balanço de calor em plantas com diferentes idades e condições ambientais: mudas em ambiente de casa de vegetação (Dal Bosco, 2001; Trejo-Chandia et al., 1997) e em ambiente protegido (Vellame, 2007); em pomares jovens, com menos de um ano de idade (Coelho Filho et al., 2005) e com pouco mais de dois anos de idade (Machado et al., 2006); e em plantas adultas a campo (Marin et al., 2001b, 2002; Rojas, 2003; Simões, 2007). Outras frutíferas também foram estudadas, utilizando-se do mesmo método, tais como: goiabeira (Silva et al., 2002), mamoeiro (Coelho Filho et al., 2003) e mangueira (Oliveira et al., 2009).

Vários fatores ambientais e fisiológicos influenciam no movimento estomático e transpiração da planta, tais como: irradiância solar, temperatura e umidade do ar, temperatura e umidade do solo, estado hídrico da planta, dentre outros (Angelocci et al., 2004; Elfving et al., 1972; Levy, 1980). Todos esses fatores, em algum grau, variam estocasticamente, e isto requer que o estômato seja capaz de perceber as mudanças que ocorrem (Farquhar \& Sharkey, 1982).

Como se sabe, as variações no ângulo zenital solar, ao longo do dia, impõem condições diferenciadas de radiação entre as faces leste e oeste das copas das plantas, o que certamente irá determinar uma resposta fisiológica diferenciada entre ambas as faces no tocante ao potencial hídrico foliar e fluxo de seiva, dentre outras. O conhecimento desses processos fisiológicos setorizados na copa poderá subsidiar informações para um melhor manejo da cultura, bem como para futuras pesquisas, além, é claro, de ampliar o conhecimento da ecofisiologia dos citros.

O trabalho teve por objetivo avaliar a influência da variação diurna e sazonal dos fatores ambientais sobre a densidade de fluxo de seiva e o potencial hídrico foliar das faces leste e oeste da copa de laranjeiras 'Valência', enxertadas sobre tangerineiras 'Cleópatra', conduzidas sem irrigação.

\section{MATERIAL E MÉTODOS}

O trabalho foi desenvolvido entre fevereiro e dezembro de 2005, na Área Experimental do Centro APTA Citros "Sylvio Moreira", do Instituto Agronômico - IAC, situada no município de Cordeirópolis, SP, nas seguintes coordenadas geográficas: $22^{\circ} 32^{\prime}$ de latitude Sul; $47^{\circ} 27^{\prime}$ de longitude Oeste, e a 639 $\mathrm{m}$ de altitude. O tipo climático da região é subtropical úmido sem estação seca, com as temperaturas médias mensais variando de $23,8^{\circ} \mathrm{C}$, no verão, a $17,1^{\circ} \mathrm{C}$, no inverno. A precipitação pluviométrica média anual é da ordem de $1.366 \mathrm{~mm}$ (Rolim et al., 2007).

O experimento foi instalado em um pomar de plantas-matrizes de laranjeiras-doces com cerca de 15 anos de idade. $\mathrm{O}$ espaçamento entre plantas foi de $8 \times 5 \mathrm{~m}$, com linha de plantio orientada no sentido norte - sul. Utilizaram-se plantas de laranjeiras 'Valência' [Citrus sinensis (L.) Osbeck] enxertadas sobre tangerineira 'Cleópatra' (Citrus reticulata Blanco), as quais estavam localizadas em uma mesma linha de plantio, uma vez que cada fileira do pomar era composta por diferentes combinações de copa/porta-enxerto. Foram utilizadas três plantas para as avaliações de fluxo de seiva e potencial hídrico do ramo. As plantas foram conduzidas em regime de sequeiro, ou seja, sem irrigação.

Os sensores para as medidas dos dados meteorológicos no interior do pomar foram instalados em dois mastros, um de cada lado da copa (leste e oeste), situados a uma altura de $2 \mathrm{~m}$ do solo e a uma distância de 0,20 $\mathrm{m}$ da copa. Os dados de radiação solar global $\left(\mathrm{Qg}, \mathrm{W} \mathrm{m}^{-2}\right)$, temperatura do ar $\left(\mathrm{Tar},{ }^{\circ} \mathrm{C}\right)$ e déficit de pressão de vapor (DPV, $\mathrm{kPa}$ ) foram coletados e armazenados em um sistema de aquisição de dados modelo CR7 (Campbell Scientific, Logan, UT, USA), com leitura a cada segundo, e média a cada 15 minutos. Para medidas de radiação solar global, utilizaram-se piranômetros modelo LI-200 (LI-COR, Lincoln, NE, USA). Para as medidas de temperatura do ar e do déficit de pressão de vapor, foram utilizados psicrômetros ventilados, construídos com tubos de PVC e junções de termopar de 
cobre-constantan, conforme descrito em Marin et al. (2001a).

As medidas de potencial hídrico foliar $\left(\Psi_{\mathrm{f}}\right.$, $\mathrm{MPa}$ ) foram realizadas com uma câmara de pressão, modelo 3005 (SoilMoisture Equipment Corp., EUA), sendo realizadas antes do amanhecer $\left(\Psi_{\mathrm{fA}}\right)$ e às $14 \mathrm{~h} 30\left(\Psi_{\mathrm{f} 14}\right)$. Em ambos os horários, foram retirados dois ramos por planta, situados na porção externa da copa: um do lado leste (nascente) e o outro do lado oeste (poente). Com o objetivo de diminuir a variabilidade entre folhas e aumentar a representatividade da amostragem do potencial hídrico foliar, em vez de folhas, optou-se por realizar as medições em ramos jovens, contendo 3-5 folhas. As avaliações foram efetuadas durante um dia de cada estação, ou seja, nos dias 17-02 (verão), 02-06 (outono), 30-08 (inverno) e 10-12 (primavera) de 2005.

As medidas de fluxo de seiva xilemático foram realizadas nas quatro estações climáticas, durante seis dias. Sensores dos modelos SGB 10, SGB16, SGB 19 e SGB 25 (Dynamax Inc., Houston, TX, EUA) foram instalados em ramos, sendo utilizados três sensores em cada face da copa. Os sensores foram conectados a um sistema de aquisição de dados modelo CR7 (Campbell Scientific, Logan, UT, USA). Para a alimentação elétrica das jaquetas térmicas dos sensores, utilizou-se um regulador portátil de voltagem de corrente contínua (AVR 3/6, Dynamax Inc., Houston, TX, EUA). As leituras dos sinais dos sensores foram realizadas a cada segundo, sendo as médias armazenadas a cada 10 minutos.

Nos cálculos de fluxo de seiva, foram utilizados os princípios envolvidos no método de balanço de calor de Sakuratani (1981), com modificações propostas por Baker \& Van Bavel (1987). Após o cálculo do fluxo de seiva (FS, $\mathrm{g} \mathrm{s}^{-1}$ ), esse foi expresso por unidade de área foliar, doravante denominado neste trabalho como densidade de fluxo de seiva (DFS, $\mathrm{g} \mathrm{m}^{-2} \mathrm{~s}^{-1}$ ). Após cada período de avaliação, foi realizada a medida da área foliar de cada ramo, nos quais os sensores de fluxo de seiva foram instalados. Para a determinação da área foliar, primeiramente, estimaram-se equações de regressão em função das medidas do maior comprimento $(\mathrm{C})$ e da maior largura (L) de folha e do produto de ambas. Foram coletadas 200 folhas ao acaso e determinadas suas medidas lineares e a sua área foliar real por meio de um planímetro digital, modelo LI 3100 (LICOR, Lincoln, NE, EUA). Embora o modelo linear envolvendo o produto tenha apresentado o maior coeficiente de determinação $\left(\mathrm{R}^{2}=0,9703\right)$, decidiu-se trabalhar com o modelo envolvendo a maior largura (L), uma vez que este também apresentou alto valor de $\mathrm{R}^{2}(0,9327)$, além de facilitar a execução dos tra- balhos de medições em campo. Deste modo, a área de cada folha foi estimada através da equação $\mathrm{AF}=$ 9,4537.L - 15,211, sendo que o somatório de AF correspondeu à área foliar total do ramo em estudo. $\mathrm{O}$ modelo proposto para determinação de AF foi testado em 100 folhas, e obteve-se alta correlação dos valores reais de AF com os valores estimados, com $r=0,977(p<0,001)$.

As médias de potencial hídrico foliar, nos períodos de avaliação, foram comparadas empregando-se o teste $t$, a um nível de significância de $5 \%$ de probabilidade.

\section{RESULTADOS E DISCUSSÃO}

O potencial hídrico foliar $\left(\Psi_{\mathrm{f}}\right)$ apresentou o mesmo padrão de resposta nos dias avaliados, sendo maior antes do amanhecer e decrescendo acentuadamente à tarde, e alcançou os menores valores na avaliação do dia 30-08-05, ou seja, durante o período de deficiência hídrica, o qual é característico para a época de inverno (Figuras 1 e 2). Esse padrão de resposta de $\Psi_{\mathrm{f}}$ está em consonância com a classificação dos citros como plantas aniso-hídricas, as quais têm um $\Psi_{\mathrm{f}}$ que diminui marcantemente com o aumento da demanda evaporativa durante o dia e é menor em plantas sob condições de estresse hídrico do que em plantas com boa disponibilidade de água no solo, ao contrário das plantas iso-hídricas, que mantêm um valor de $\Psi_{\mathrm{f}}$ quase constante durante o dia, independentemente do estado hídrico do solo (Tardieu \& Simoneau, 1998). Vale salientar que outros fatores, também típicos de ocorrência no inverno, tais como baixas temperaturas do ar e do solo, poderiam estar contribuindo para o decréscimo de $\Psi_{\mathrm{f}}$. Durante o período experimental, a temperatura do solo variou entre 18,7 e $27,5^{\circ} \mathrm{C}$, a $40 \mathrm{~cm}$ de profundidade (em julho e fevereiro, respectivamente), e entre 11,9 e $21,8^{\circ} \mathrm{C}$, a $5 \mathrm{~cm}$ de profundidade (em julho e janeiro, respectivamente) (Figura 1B). De fato, temperaturas do solo abaixo de $15^{\circ} \mathrm{C}$ reduzem a absorção de água pelas raízes dos citros (Elfving \& Kaufmann, 1972; Syvertsen, 1982; Syvertsen et al., 1983), induzindo a menores valores de $\Psi_{\mathrm{f}^{\circ}}$

Os potenciais hídricos foliares medidos antes do amanhecer $\left(\Psi_{\mathrm{fA}}\right)$ foram semelhantes para os meses de fevereiro, junho e dezembro, variando entre -0,31 e -0,48 MPa, enquanto em agosto o valor obtido foi duas a três vezes menor, ou seja, cerca de -1,1 MPa. Em todas as avaliações, os valores de $\Psi_{\mathrm{fA}}$ entre as faces da copa não apresentaram diferenças significativas ( $\mathrm{p}>0,05)$, indicando que a reidratação dos tecidos que normalmente acontece durante o período da noite, acontece uniformemente 
na copa da planta.

Em relação aos valores de potencial hídrico foliar obtidos às $14 \mathrm{~h} 30\left(\Psi_{\mathrm{fl} 4}\right)$ (Figura $\left.2 \mathrm{~B}\right)$, estes foram menores $(\mathrm{p}<0,01)$ do que os medidos antes do amanhecer, fato que se verificou em todas as épocas avaliadas. $\mathrm{O}$ menor valor de $\Psi_{\mathrm{fl} 14}$ ocorreu no dia 30-08-05, alcançando -1,89 $\mathrm{MPa}$, enquanto o maior $\Psi_{\mathrm{f} 14}$ foi verificado no dia 10-12-05, com valor de $-0,95 \mathrm{MPa}$. À medida que a planta perde água para a atmosfera via transpiração, vai ocorrendo aumento na tensão da coluna de água no interior dos vasos de xilema. Essa variação diurna de $\Psi_{\mathrm{f}}$ ocorre mesmo em plantas com boa disponibilidade hídrica no solo e, em média, esses valores de $\Psi_{\mathrm{f}}$, em laranjeira 'Valência', variam entre -0,4 e -2,4 $\mathrm{MPa}$ ao longo do dia (Syvertsen \& Albrigo, 1980; Ribeiro, 2006).

Em todas as avaliações realizadas às $14 \mathrm{~h} 30$, a face oeste da copa apresentou menores $(\mathrm{p}<0,05)$ valores de $\Psi_{\text {f14 }}$ quando comparados aos obtidos na face leste. Em trabalho com laranjeira 'Valência', Ribeiro (2006) também obteve menores $(p<0,05)$ valores de $\Psi_{\mathrm{f} 14}$ na face oeste, tanto em plantas irrigadas, quanto em condições de sequeiro. A incidência solar direta, aliada a maior temperatura e a menor umidade relativa do ar, no período da tarde, são fatores que levam ao aumento da diferença de pressão de vapor entre a folha e o ar na face oeste, redundando em maior transpiração e a consequente redução de $\Psi_{\mathrm{f} 14}$.

O dia 02-06-05 apresentou os maiores decréscimos de $\Psi_{\mathrm{f}}$ quando considerados os valores de antes do amanhecer $\left(\Psi_{\mathrm{fA}}\right)$ e das $14 \mathrm{~h} 30\left(\Psi_{\mathrm{fl} 14}\right)$, e correspondeu 3,1 e 4,1 vezes nas faces leste e oeste, respectivamente. Os menores decréscimos de $\Psi_{\mathrm{f}}$ verificaram-se no dia 30-08-05, sendo de 1,7 e 1,9 vez, respectivos às faces leste e oeste.

A Figura 3 mostra a variação diária da densidade de fluxo de seiva (DFS) em intervalos de 30 minutos, nas faces leste e oeste da copa, para um dia de céu claro e para um dia nublado dos meses de fevereiro, maio, agosto e dezembro de 2005. Nos dias ensolarados, como era de se esperar, observase claramente a defasagem entre os ciclos diurnos da densidade de fluxo de seiva das faces leste e oeste da copa (Figura 3A,C,E,G). Essa defasagem reflete a diferença na incidência da radiação solar entre ambas as faces da copa durante o percurso do Sol na abóbada celeste ao longo do dia. Enquanto a face leste se encontra iluminada durante toda a manhã, a face oeste encontra-se sombreada durante boa parte do período matutino, invertendo-se esse padrão de disponibilidade energética das faces durante o período da tarde (Figura 4A,C,E,G). O padrão de variação da DFS, para o dia ensolarado de 22-02-05, apresentou, para a face leste, rápido incremento a partir das $7 \mathrm{~h} 30$, e prosseguiu linearmente até às $9 \mathrm{~h} 30$, continuando com pequenos aumentos até alcançar o seu valor máximo, às $11 \mathrm{~h} 30$ (74,34 g $\left.\mathrm{m}^{-2} 30 \mathrm{~min}^{-1}\right)$. Em seguida, verificaram-se reduções graduais até o início da noite. Na face oeste, houve aumento progressivo e praticamente linear até atingir o seu pico, às $14 \mathrm{~h}\left(108,01 \mathrm{~g} \mathrm{~m}^{-2} 30 \mathrm{~min}^{-1}\right)$, diminuindo lentamente até às $16 \mathrm{~h} 30$, quando, então, ocorreram decréscimos acentuados (Figura 3A). A diferença de temperatura do ar entre ambas as faces foi de $4^{\circ} \mathrm{C}$, às $15 \mathrm{~h}$. A temperatura máxima do dia 22-02-05 foi de $33,1^{\circ} \mathrm{C}$, na face oeste, e de $29,8^{\circ} \mathrm{C}$, na face leste, ambas ocorridas às $13 \mathrm{~h} 30$. Para o déficit de pressão de vapor do ar (DPV), o valor máximo foi de 2,37 $\mathrm{kPa}$, ocorrido às $15 \mathrm{~h} 30$, na face oeste. Já para a face leste, o máximo DPV ocorreu às $14 \mathrm{~h} 30$, alcançando o valor de $1,94 \mathrm{kPa}$.

Para o dia nublado de 18-02-05, a variação da densidade de fluxo de seiva nas faces leste e oeste, durante o período da manhã, foi bastante similar, tanto em relação aos valores quanto ao padrão de variação ocorridos no dia ensolarado para o período considerado (Figura 3B). Isto deveu-se ao fato de, no dia nublado, ter ocorrido céu claro durante toda a manhã, com nebulosidade somente no período da tarde (Figura 4B), sendo esta característica bem típica de verão. No período da tarde, as oscilações bruscas na densidade de fluxo de seiva, principalmente para a face oeste, foram motivadas pelas oscilações da radiação solar. A diferença máxima de temperatura entre as faces foi de aproximadamente $1,2^{\circ} \mathrm{C}$, às $10 \mathrm{~h}$ 30 . $\mathrm{O}$ valor máximo da temperatura do ar ocorreu às $13 \mathrm{~h} 30$, alcançando valores de 33,3 e $33^{\circ} \mathrm{C}$ para as faces leste e oeste, respectivamente. As pequenas diferenças de DPV verificadas entre as faces foram decorrentes das diferenças de temperatura das mesmas. Os valores máximos de DPV foram de 1,71 e 1,55 $\mathrm{kPa}$ para as faces leste e oeste, respectivamente.

Para o dia ensolarado da avaliação realizada em 27-05-05, a densidade de fluxo de seiva da face leste começou a acentuar-se às 8h 30 (Figura 3C), ou seja, uma hora e meia após o nascer do Sol, e aumentou de forma repentina e linear até às $11 \mathrm{~h}\left(70,90 \mathrm{~g} \mathrm{~m}^{-2} 30 \mathrm{~min}^{-1}\right)$, quando, então, passou a declinar de maneira gradual até o final da tarde. Já para a face oeste, a DFS acentuou-se por volta das $10 \mathrm{~h}$ e, à semelhança da face leste, prosseguiu aumentando linearmente, porém de maneira menos intensa, atingindo o ápice do fluxo por volta das $14 \mathrm{~h}$ $30\left(88,46 \mathrm{~g} \mathrm{~m}^{-2} 30 \mathrm{~min}^{-1}\right)$ e mantendo-se praticamente neste platô até às $15 \mathrm{~h} 30$, quando, então, se verifica um declínio acentuado do fluxo até às $18 \mathrm{~h}$. Como 
as temperaturas verificadas neste dia foram amenas, não ultrapassando os $24,5^{\circ} \mathrm{C}$, as diferenças entre as faces foram de menor intensidade que as ocorridas em fevereiro, alcançando valor máximo de $2,36^{\circ} \mathrm{C}$. A face leste apresentou temperatura máxima de $24,1^{\circ} \mathrm{C}$. A variação do DPV entre as faces espelhou fielmente o verificado para a temperatura, apresentando diferença máxima de $0,17 \mathrm{kPa}$. Os picos de DPV foram de 1,23 e 1,26 kPa, na faces leste e oeste, respectivamente, ocorridos às $14 \mathrm{~h}$.

Com relação ao dia nublado de 30-05-05, tanto para a DFS quanto para a radiação solar, praticamente não houve diferença entre as faces avaliadas. Em virtude da intensa nebulosidade ocorrida ao longo de todo o dia (Figura 4D), houve o predomínio da radiação difusa, que promoveu uma distribuição uniforme da energia radiante entre as faces da copa, refletindo, tal fato, num padrão idêntico para o fluxo de seiva (Figura 3D). As temperaturas apresentaram pouca variação ao longo do dia, com máxima de $22,6^{\circ} \mathrm{C}$, para a face leste, e de $23,2^{\circ} \mathrm{C}$, para a oeste. A demanda evaporativa da atmosfera do dia 30-0505 foi muito baixa, com valor máximo de DPV de $0,53 \mathrm{kPa}$, verificado às $16 \mathrm{~h}$.

Para o dia de céu claro da avaliação realizada em 28-08-05, observou-se que a DFS, para a face leste da copa, aumentou repentinamente, e de forma linear, até às $9 \mathrm{~h}$, já atingindo $85,7 \%$ do seu valor máximo, que só ocorreu às $12 \mathrm{~h}\left(65,66 \mathrm{~g} \mathrm{~m}^{-2} 30 \mathrm{~min}^{-1}\right)$. Após esse horário, verificou-se um decréscimo gradual até estabilizar-se por volta das $18 \mathrm{~h} 30$ (Figura 3E). Para a face oeste, a DFS também começou a aumentar a partir das 7 h 30 e prosseguiu de forma lenta e gradual até alcançar o valor máximo de 42,54 $\mathrm{g} \mathrm{m}^{-2} 30 \mathrm{~min}^{-1}$, às $14 \mathrm{~h}$, mantendo-se praticamente estacionária neste patamar até às $16 \mathrm{~h}$, decaindo rapidamente após este horário (Figura $3 \mathrm{E}$ ). $\mathrm{O}$ dia 28-08-05 apresentou temperaturas elevadas, no qual a máxima da face leste foi de $31,5^{\circ} \mathrm{C}$, e de $35,1^{\circ} \mathrm{C}$, na face oeste, ambas ocorridas às $15 \mathrm{~h}$. A temperatura da face oeste suplantou a da face leste em até $3,84^{\circ} \mathrm{C}$, às $16 \mathrm{~h}$. As diferenças de DPV verificadas entre as faces das copas refletiram, similarmente, as diferenças observadas nas temperaturas do ar. O DPV da face oeste foi superior à leste em $0,45 \mathrm{kPa}$, ocorrido às $16 \mathrm{~h}$. Os valores máximos foram de 2,81 e 3,23 $\mathrm{kPa}$, para as faces leste e oeste, respectivamente, ocorridos às $15 \mathrm{~h} 30$.

O dia 27-08-05 foi de intensa nebulosidade (Figura 4F) e de alta umidade relativa do ar durante todo o período da manhã, o que ocasionou praticamente a ausência de DFS no período matutino. No período da tarde, em resposta aos pequenos aumentos verificados na energia radiante (Figura
4F), temperatura do ar e DPV, a DFS começou a ocorrer a partir das $12 \mathrm{~h} 30$, e seguiu aumentando até atingir o seu máximo por volta das $15 \mathrm{~h} 30$, declinando gradualmente em seguida (Figura 3F). Observou-se, ainda, que os cursos diários da DFS foram similares em ambas as faces, cujos valores máximos foram de 27,57 e 25,80 $\mathrm{g} \mathrm{m}^{-2} 30 \mathrm{~min}^{-1}$, para as faces leste e oeste, respectivamente. As temperaturas variaram de 14 a $24,4^{\circ} \mathrm{C}$, enquanto o DPV máximo foi de $0,59 \mathrm{kPa}$.

Observando-se os cursos diários da DFS para o dia ensolarado de 14-12-05, verifica-se que, na face leste da copa, a DFS começou a intensificarse a partir das $6 \mathrm{~h} 30$ e prosseguiu aumentando rapidamente, de forma praticamente linear, até às $9 \mathrm{~h} 30$, alcançando o seu valor máximo: $92,55 \mathrm{~g} \mathrm{~m}^{-2} 30 \mathrm{~min}^{-1}$. Após esse horário, e até às 16 h, a DFS apresentou oscilações no seu comportamento motivadas pelas variações ocorridas nas condições ambientais, decaindo, após isso, de maneira gradual. Para a face oeste, o fluxo de seiva acentuou-se a partir das $7 \mathrm{~h}$ e continuou a aumentar, lenta e gradualmente, até atingir o seu valor máximo, de 73,94 $\mathrm{g} \mathrm{m}^{-2}$ $30 \mathrm{~min}^{-1}$, às $14 \mathrm{~h} 30$, decaindo acentuadamente em seguida (Figura 3G). Embora o dia 14-12-05, aqui representado como dia ensolarado, tenha mostrado variações na radiação solar decorrentes da presença de nuvens a partir das $10 \mathrm{~h}$ (Figura 4G), este foi o dia, dentre os seis avaliados em dezembro, que apresentou maior valor integrado de radiação solar. As diferenças de temperatura entre as faces da copa foram relativamente pequenas, sendo a diferença máxima de $1,33^{\circ} \mathrm{C}$. As temperaturas máximas foram de $29,5^{\circ} \mathrm{C}$, na face leste, e $30,7^{\circ} \mathrm{C}$, na face oeste, ocorridas às $14 \mathrm{~h} 30$. Os valores máximos de DPV foram de 1,65 e $1,80 \mathrm{kPa}$, ocorridos às $14 \mathrm{~h} 30$, para as faces leste e oeste, respectivamente.

Com relação ao dia nublado de 11-12-05, o comportamento dos cursos diários da DFS entre ambas as faces da copa foi bastante similar, e a maior disponibilidade de energia radiante no período da tarde (Figura $4 \mathrm{H}$ ) promoveu um fluxo mais intenso, cujos valores máximos obtidos em cada face foi de $48,71 \mathrm{~g} \mathrm{~m}^{-2} 30 \mathrm{~min}^{-1}$, na leste, e de $51,18 \mathrm{~g} \mathrm{~m}^{-2} 30 \mathrm{~min}^{-1}$, na oeste (Figura $3 \mathrm{H}$ ). As temperaturas variaram de 17,7 a $25,3^{\circ} \mathrm{C}$, e o DPV máximo foi de $0,77 \mathrm{kPa}$.

De modo geral, nos dias ensolarados, a DFS da face leste atingiu o seu máximo por volta das 11$12 \mathrm{~h}$, enquanto, na face oeste, o pico da DFS ocorreu ao redor das 14-14h 30. Esses resultados concordam com os obtidos por Machado et al. (2006), que, ao avaliarem o fluxo de seiva da planta inteira de laranjeira 'Natal', ou seja, com os sensores instalados 
no tronco da planta, obtiveram valores máximos de DFS entre 12 e 14 h. Uma vez que a DFS da planta inteira corresponde à média dos valores obtidos em cada face da copa, o seu valor máximo ocorrerá entre os horários de pico de cada face. Já para os dias nublados, devido á predominância da radiação difusa, o curso diário da DFS foi praticamente similar em ambas as faces da copa.

Nos dias ensolarados, o rápido aumento da DFS no lado leste da copa está respondendo ao aumento da radiação global, o qual promove aumento da abertura estomática e o consequente aumento da transpiração, até atingir a saturação. Em condições subtropicais, independentemente da estação climática, os valores máximos de condutância estomática são verificados por volta das 9-10h 30 (Machado et al., 2006, 2007; Ribeiro, 2006). Atingida a saturação lumínica da condutância estomática, o aumento da DFS passa a responder ao aumento da demanda evaporativa do ar (DPV e temperatura) até atingir o seu máximo, por volta das 11-12 h. A partir desse horário, o desbalanço entre o total de água transpirada e o total de água absorvida pela face leste, durante o período matutino, induz acentuado déficit hídrico foliar, ocasionando rígido controle estomático para evitar a desidratação excessiva dos tecidos dessa face. O indício desse desbalanço é a diferença de $\Psi_{\mathrm{f}}$ ao longo do dia, variando entre $-0,56$ e $-0,84$ $\mathrm{kPa}$ (Figura 2).

Na face oeste, o lento aumento da DFS na parte inicial da manhã está sendo limitado pelos baixos níveis de radiação solar devido ao sombreamento em que essa face se encontra. Quando a radiação passa a ser não limitante para a abertura estomática, o que geralmente ocorre entre 10-11 h, o aumento da DFS indica estar sendo em função do aumento da transpiração promovida, principalmente, pelo aumento do DPV. A DFS continua a aumentar até alcançar o seu pico, por volta das 14-14h 30, quando o potencial hídrico foliar atinge os valores mais negativos (Figura 2B), induzindo à ativação de mecanismos de controle estomático da transpiração, a fim de evitar a desidratação excessiva dos tecidos da face oeste, prevenindo, assim, disfunções fisiológicas à planta, como, por exemplo, a cavitação dos vasos do xilema. As reduções em DFS, logo após o seu pico, parecem estar respondendo ao controle estomático e à redução da demanda evaporativa, a qual se verifica após as $15-15 \mathrm{~h} 30$, sendo que, mais para o final da tarde, a DFS passa a responder às limitações de radiação (Figura 4A,C,E,G).

$\mathrm{Na}$ avaliação do dia 28-08-05 (Figura 3E), os valores de DFS da face oeste foram menores que o da face leste. Nessa época, as plantas encontravam- se menos hidratadas (Figuras 2A e 1D), e à medida que o $\Psi_{\mathrm{fA}}$ decresce, não apenas o valor máximo da condutância estomática diminui, mas também a abertura torna-se mais confinada às primeiras horas da manhã, quando a temperatura e o DPV exercem menor demanda evaporativa (Eamus, 1999), o que permite maiores valores de transpiração. À tarde, o forte aumento na demanda evaporativa promove restrições adicionais na abertura estomática, reduzindo sensivelmente os valores de transpiração.

Em 14-12-05, também foram observados menores valores de DFS na face oeste (Figura 3G). Uma vez que as plantas se encontravam bem hidratadas (Figura 2A) e sob condições de demanda evaporativa intermediária, era de se esperar maiores intensidades de DFS na face oeste. Porém, como esse dia apresentou oscilações acentuadas na radiação durante o período da tarde (Figura 4G), esse fato, provavelmente, pode ter contribuído para as reduções nos valores esperados de DFS, uma vez que decréscimos na radiação global ocasionam decréscimos na demanda evaporativa do ar.

Já para os dias nublados, devido à predominância da radiação difusa, o curso diário de DFS foi praticamente similar em ambas as faces da copa, o que concorda com Ribeiro et al. (2005), que afirmam não haver diferença significativa na energia disponível entre as faces da copa de laranjeira em dias de alta nebulosidade. 

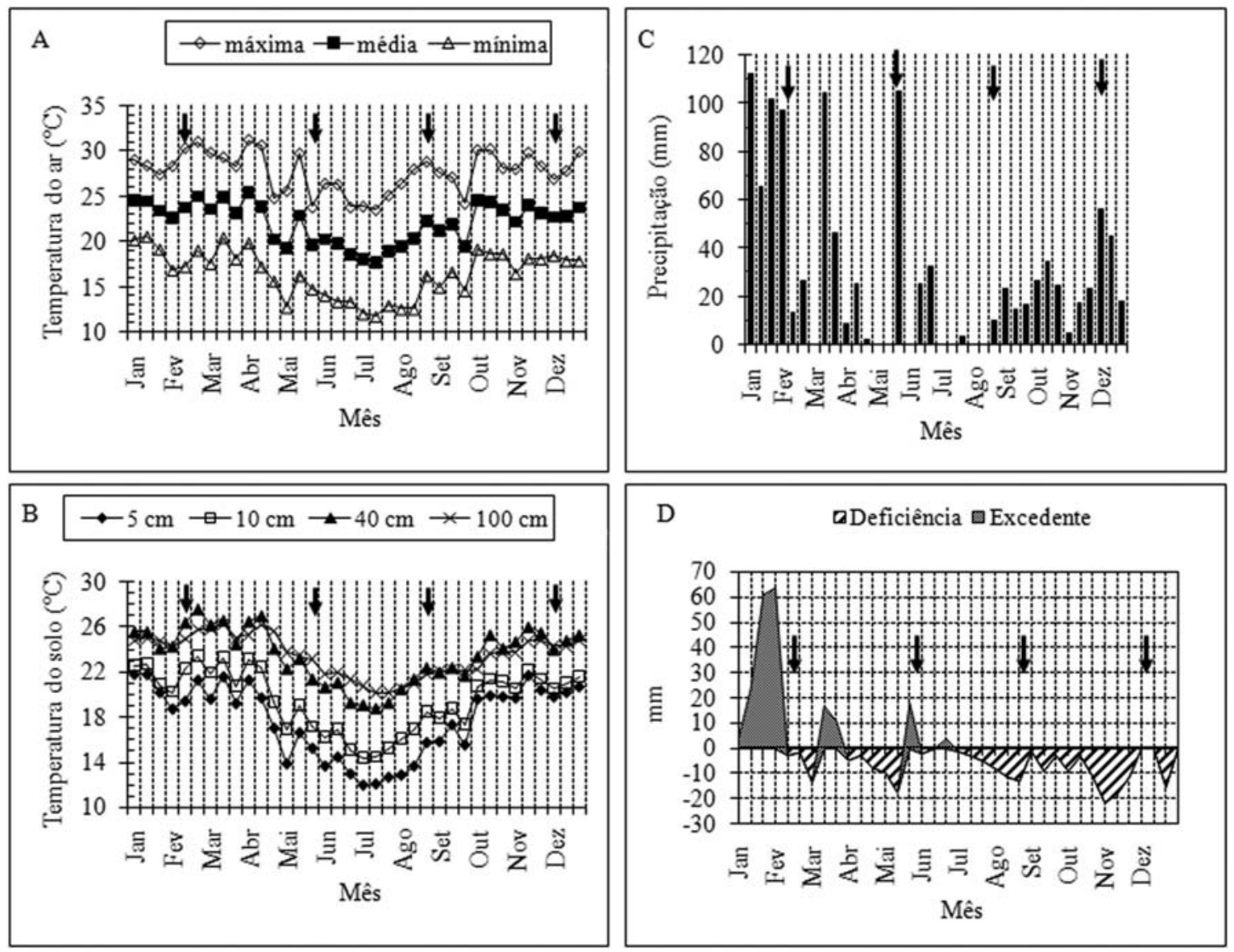

FIGURA 1 - Temperatura do ar (A) e do solo (B), precipitação (C) e extrato do balanço hídrico climatológico (D) durante 2005, em Cordeirópolis (SP). Os símbolos representam o valor médio decendial (A e B), as barras representam o somatório decendial (C) e os valores positivos indicam excedentes hídricos (incluindo a reposição de água) e negativos a deficiência hídrica (incluindo a retirada de água), calculados a partir de dados decendiais (D). Capacidade de água disponível $(C A D)$ de $100 \mathrm{~mm}$. As setas indicam as épocas das avaliações. Dados obtidos em estação meteorológica convencional (CIIAGRO/IAC) localizada a $500 \mathrm{~m}$ do campo experimental. 

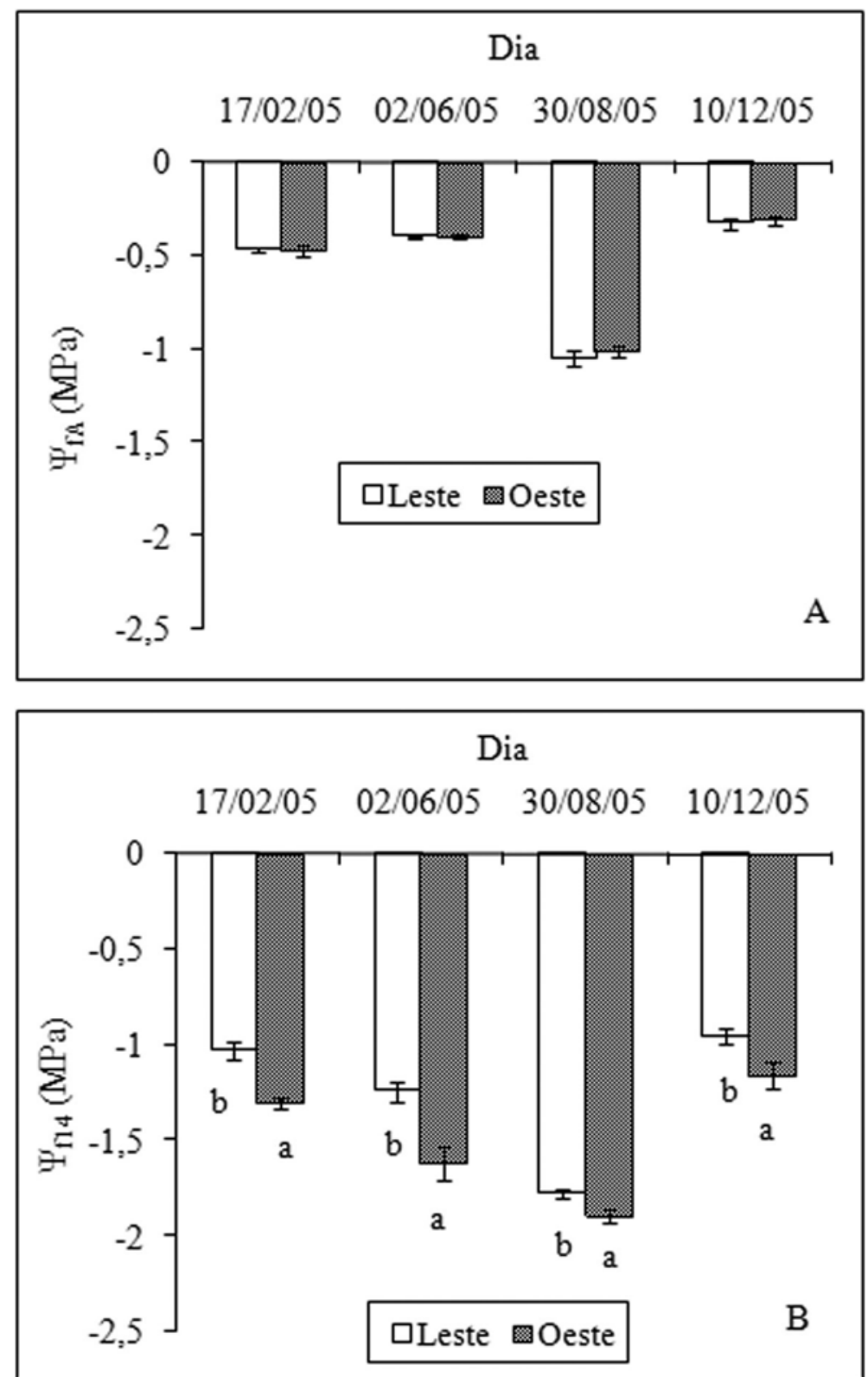

FIGURA 2 - Variação do potencial hídrico foliar $\left(\Psi_{\mathrm{f}}\right)$ de laranjeiras 'Valência' em condições de campo, conduzidas sem irrigação. As medidas foram efetuadas antes do amanhecer $\left(\Psi_{\mathrm{fA}}\right.$, em $\left.\mathrm{A}\right)$ e às $14 \mathrm{~h} 30\left(\Psi_{\mathrm{fl} 4}\right.$, em B) nas faces leste e oeste da copa, em quatro épocas (dia), durante o ano de 2005. Barras indicam o valor médio $(n=3) \pm$ erro- padrão. Em $B$, médias sinalizadas por letras distintas, nas colunas de cada dia, representam diferenças significativas, pelo teste- $t$ $(\mathrm{p}<0,05)$. 


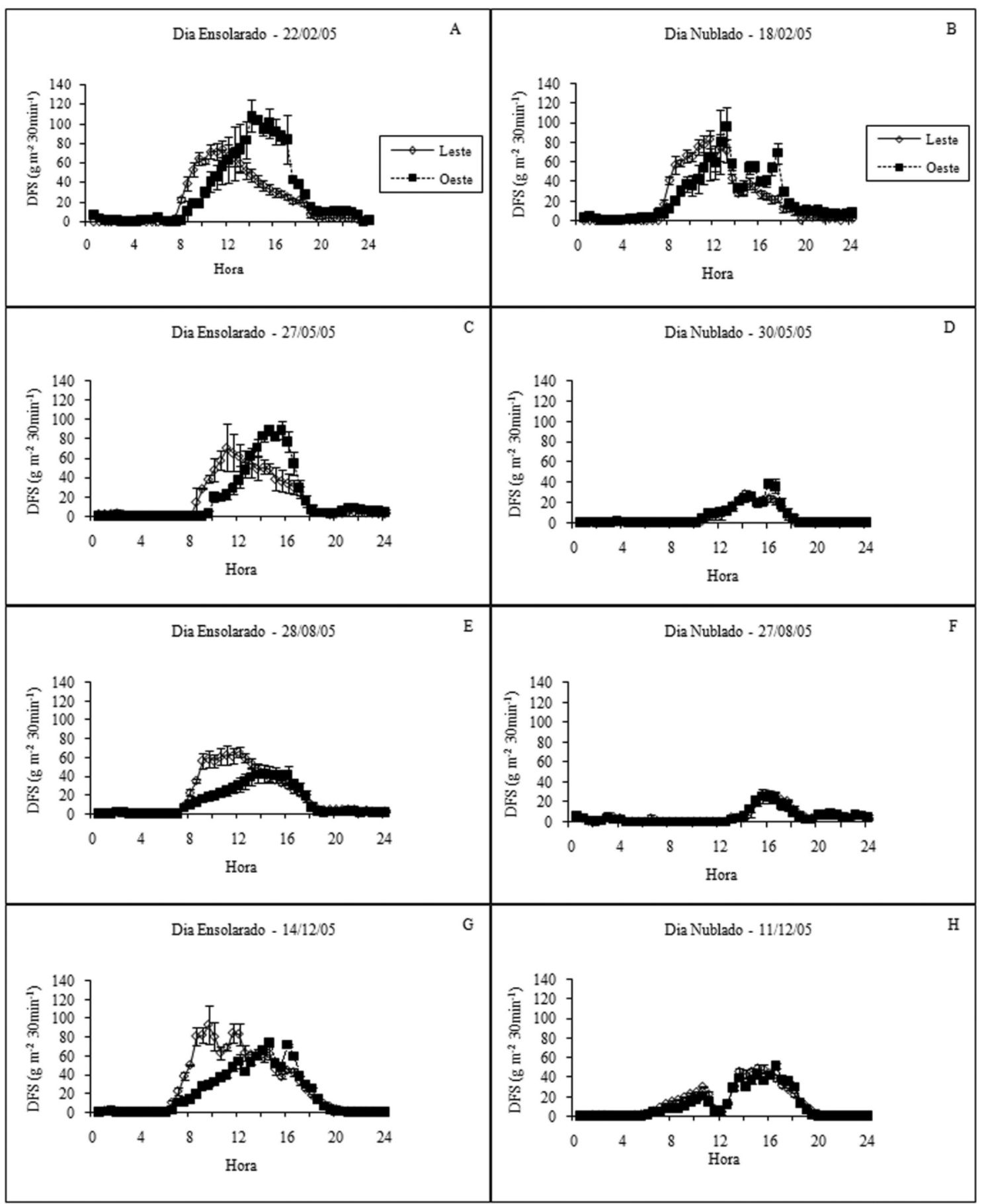

FIGURA 3 - Curso diário da densidade de fluxo de seiva (DFS) das faces leste e oeste da copa de laranjeiras 'Valência' em condições de campo, conduzidas sem irrigação, durante um dia ensolarado (A,C,E,G) e um dia nublado (B,D,F,H), dos meses de fevereiro, maio, agosto e dezembro de 2005. Símbolos indicam valor médio $(n=2-3) \pm$ erro-padrão. 


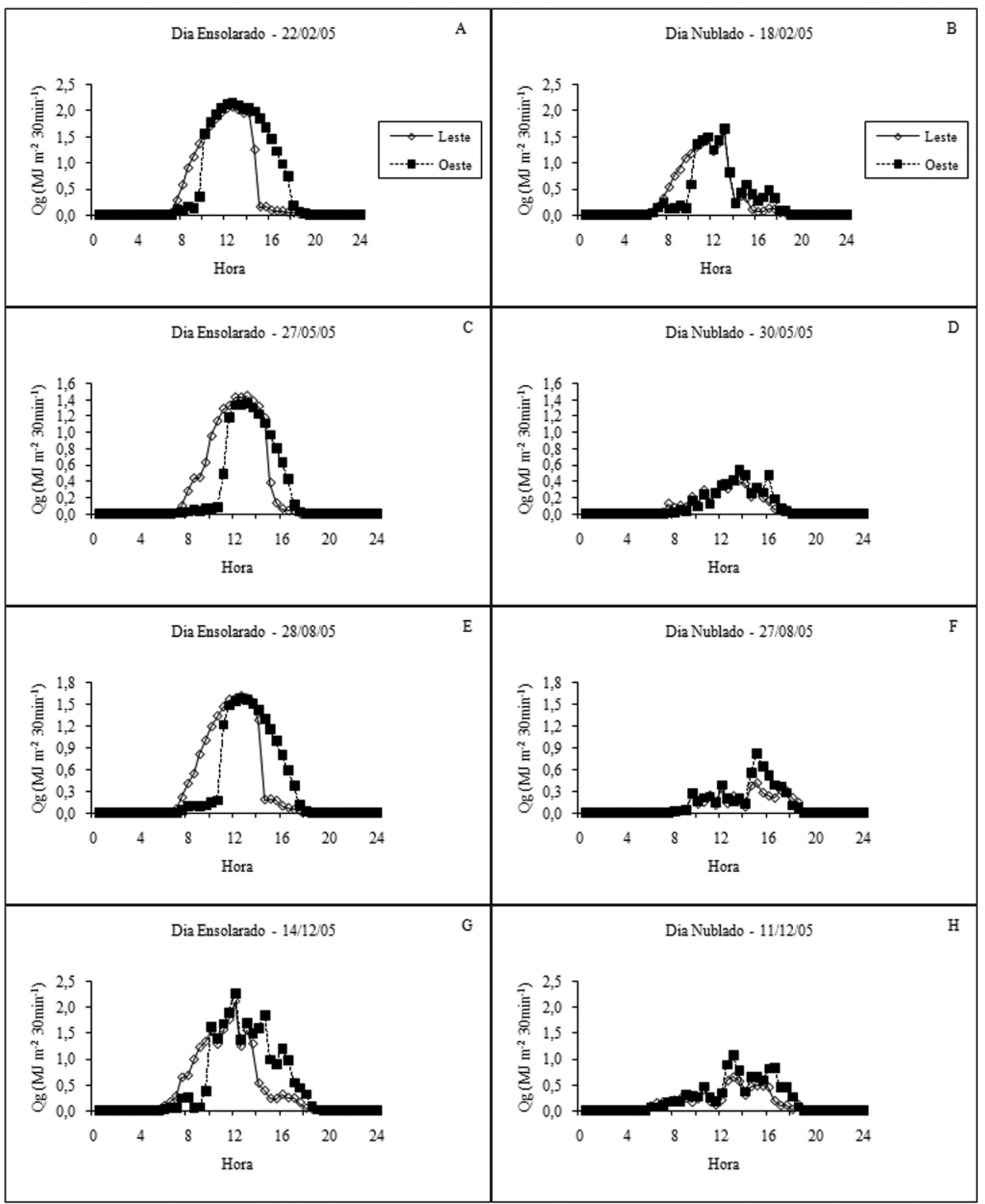

FIGURA 4 - Curso diário da radiação solar global (Qg) das faces leste e oeste da copa de laranjeiras 'Valência’ em condições de campo, conduzidas sem irrigação, durante um dia ensolarado (A,C,E,G) e um dia nublado (B,D,F,H), dos meses de fevereiro, maio, agosto e dezembro de 2005. 


\section{CONCLUSÃO}

A maior demanda evaporativa que se verifica no período da tarde, induz a maior déficit hídrico na face oeste da copa, independentemente da época do ano e, por consequência, maior densidade de fluxo de seiva (DFS) em plantas bem hidratadas sob condições de dias completamente ensolarados. Em plantas em condições de deficiência hídrica (indicada por baixos valores de $\Psi_{\mathrm{f}}$ ), a face oeste é mais sensível a essa situação, apresentando redução de DFS. Essa redução ocorre no inverno, na região de Cordeirópolis (SP).

\section{AGRADECIMENTOS}

À Fapesp, pelo apoio financeiro. Ao CNPq, pela Bolsa de Produtividade concedida a E. C. Machado e a R.V. Ribeiro. Ao José Zanetti Júnior, pela valiosa assistência durante a condução do experimento.

\section{REFERENCIAS}

ANGELOCCI, L.R.; MARIN, F.R.; OLIVEIRA, R.F.; RIGHI, E.Z. Transpiration, leaf diffusive conductance, and atmospheric water demand relationship in an irrigated acid lime orchard. Brazilian Journal of Plant Physiology, Londrina, v.16, n.1, p.53-64, 2004.

BAKER, J.M.; VAN BAVEL, C.H.M. Measurement of mass flow of water in the stems of herbaceous plants. Plant, Cell and Environment, Oxford, v.10, n.9, p.777-782, 1987.

COELHO FILHO, M.A.; ANGELOCCI, L.R.; CAMPECHE, L.F.S.M.; FOLEGATTI, M.V.; BERNARDES, M.S. Field determination of young acid lime plants transpiration by the stem heat balance method. Scientia Agricola, Piracicaba, v.62, n.3, p.240-247, 2005.

COELHO FILHO, M.A.; CASTRO NETO, M.T.; COELHO, E.F. Transpiração máxima de plantas de mamão (Carica Papaya L.) em pomar fertirrigado, nas condições de Cruz das Almas-BA. In: CONGRESSO NACIONAL DE IRRIGAÇÃO E DRENAGEM, 13., 2003, Juazeiro. Anais... Viçosa: ABID, 2003. CD-ROM.

DAL BOSCO, A. Fluxo de seiva em laranjeira (Citrus sinensis L. Osb.) 'Pera' infectada com Xylella fastidiosa Wells. 2001. 53 f. Dissertação
(Mestrado em Fisiologia e Bioquímica de Plantas) - Escola Superior de Agricultura "Luiz de Queiroz", Universidade de São Paulo, Piracicaba, 2001.

EAMUS, D. Ecophysiological traits of deciduous and evergreen woody species in the seasonally dry tropics. Trends in Ecology and Evolution, London, v.14, p.11-16, 1999.

ELFVING, D.C.; KAUFMANN, M.R. Diurnal and seasonal effects of environment on plant water relations and fruit diameter of citrus. Journal of the American Society for Horticultural Science, Alexandria, v.97, n.5, p.566-570, 1972.

ELFVING, D.C.; KAUFMANN, M.R.; HALL, A.E. Interpreting leaf water potential measurements with a model of the soil-plant-atmosphere continuum. Physiologia Plantarum, Copenhagen, v.27, n.2, p.161-168, 1972.

FARQUHAR, G.D.; SHARKEY, T.D. Stomatal conductance and photosynthesis. Annual Review of Plant Physiology, Palo Alto, v.33, p.317-345, 1982.

GRIME, V.L.; SINCLAIR, F.L. Sources of error in stem heat balance sap flow measurements. Agricultural and Forest Meteorology, Amsterdam, v.94, n.2, p.103-121, 1999.

LEVY, Y. Effect of evaporative demand on water relations of Citrus limon. Annals of Botany, Oxford, v.46, n.6, p.695-700, 1980.

MACHADO, E.C.; OLIVEIRA, R.F.; RIBEIRO, R.V.; MEDINA, C.L.; STUCHI, E.S.; MARIN, F.R.; SILVA, J.A.B.; SILVA, S.R. Fluxo de seiva e fotossíntese em laranjeira 'Natal' com clorose variegada dos citros. Pesquisa Agropecuária Brasileira, Brasília, v.41, n.6, p.911-918, 2006.

MACHADO, E.C.; OLIVEIRA, R.F.; RIBEIRO, R.V.; MEDINA, C.L.; STUCHI, E.S.; PAVANI, L.C. Deficiência hídrica agrava os sintomas fisiológicos da clorose variegada dos citros em laranjeira 'Natal'. Bragantia, Campinas, v.66, p.373-379, 2007.

MARIN, F.R.; ANGELOCCI, L.R.; COELHO FILHO, M.A.; VILLA NOVA, N.A. Construção e avaliação de psicrômetro aspirado de termopar. Scientia Agrícola, Piracicaba, v.58, n.4, p.839-844, 2001a. 
MARIN, F.R.; ANGELOCCI, L.R.; PEREIRA, A.R.; VILLA NOVA, N.A.; SENTELHAS, P.C. Sap flow and evapotranspiration in an irrigated citrus orchard. Revista Brasileira de Agrometeorologia, Santa Maria, v.9, n.2, p.219-226, 2001 b.

MARIN, F.R.; ANGELOCCI, L.R.; PEREIRA, A.R; SENTELHAS, P.C.; VILLA NOVA, N.A. Balanço de energia e consumo hídrico em pomar de limaácida 'Tahiti'. Revista Brasileira de Meteorologia, São José dos Campos, v.17, n.2, p.219-228, 2002.

MARIN, F.R.; RIBEIRO, R.V.; ANGELOCCI, L.R.; RIGHI, E.Z. Fluxo de seiva pelo método do balanço de calor: base teórica, qualidade das medidas e aspectos práticos. Bragantia, Campinas, v.67, n.1, p.1-14, 2008.

OLIVEIRA, G.X.S.; COELHO FILHO, M.A.; PEREIRA, F.A.C.; COELHO, E.F.; PAZ, V.P.S.; CASTRO NETO, M.T. Relações entre transpiração máxima, evapotranspiração de referência e área foliar em quatro variedades de mangueira. Revista Brasileira de Fruticultura, Jaboticabal, v.31, n.1, p.20-27, 2009.

RIBEIRO, R.V. Variação sazonal da fotossíntese e relações hídricas de laranjeira 'Valência'. 2006. 157 f. Tese (Doutorado em Física do Ambiente Agrícola) - Escola Superior de Agricultura "Luiz de Queiroz", Universidade de São Paulo, Piracicaba, 2006.

RIBEIRO, R.V.; MACHADO, E.C.; SANTOS, M.G. Leaf temperature in sweet orange plants under field conditions: influence of meteorological elements. Revista Brasileira de Agrometeorologia, Santa Maria, v.13, n.3, p.393-403, 2005.

ROJAS, J.S.D. Avaliação do uso do fluxo de seiva e da variação do diâmetro do caule e de ramos na determinação das condições hídricas de citros, como base para o manejo de irrigação. 2003. 110 f. Tese (Doutorado em Agronomia) - Escola Superior de Agricultura "Luiz de Queiroz", Universidade de São Paulo, Piracicaba, 2003.

ROLIM, G.S.; CAMARGO, M.B.P.; LANIA, D.G.; MORAES, J.F.L. Classificação climática de Köppen e de Thornthwaite e sua aplicabilidade na determinação de zonas agroclimáticas para o Estado de São Paulo. Bragantia, Campinas, v.66, n.4, p.711-720, 2007.
SAKURATANI, T. A heat balance method for measuring water flux in the stem of intact plants. Journal of Agricultural Meteorology, Tokyo, v.37, n.1, p.9-17, 1981.

SIMÕES, W.L. Influência de diferentes sistemas de microaspersão na distribuição de água no solo e nas respostas morfofisiológicas do Citrus latifolia Tanaka sobre o porta-enxerto Citrus limonia Osbeck. 2007. 114 f. Tese (Doutorado em Engenharia Agrícola) - Universidade Federal de Viçosa, Viçosa, MG, 2007.

SILVA, B.B.; MOURA, M.S.B.; AZEVEDO, P.V.; SOARES, J.M. Medidas de transpiração de um pomar de goiabeiras pelo método do balanço de calor caulinar. Revista Brasileira de Agrometeorologia, Santa Maria, v.10, n.1, p.19-27, 2002.

SYVERTSEN, J.P. Minimum leaf water potential and stomatal closure in citrus leaves of different ages. Annals of Botany, Oxford, v.49, n.6, p.827834, 1982.

SYVERTSEN, J.P.; ALBRIGO, L.G. Seasonal and diurnal citrus leaf and fruit water relations. Botanical Gazette, Chicago, v.141, n.4, p.440-446, 1980.

SYVERTSEN, J.P.; ZABLOTOWICZ, R.M.; SMITH JUNIOR, M.L. Soil temperature and flooding effects on two species of citrus 1. Plant growth and hydraulic conductivity. Plant and Soil, Dordrecht, v.72, n.1, p.3-12, 1983.

TARDIEU, F.; SIMONNEAU, T. Variability among species of stomatal control under fluctuating soil water status and evaporative demand: modelling isohydric and anisohydric behaviours. Journal of Experimental Botany, Oxford, v.49, p.419-432, 1998.

TREJO-CHANDIA, J.E.; ANGELOCCI, L.R.; OLIVEIRA, R.F. Aplicação do método de balanço de calor na determinação da transpiração de mudas de limoeiro. Scientia Agrícola, Piracicaba, v.54, n.3, p.221-231, 1997.

VELLAME, L.M. Transpiração em plantas de laranja e manga utilizando sonda de dissipação térmica e sensor de balanço de calor caulinar. 2007. 67 f. Dissertação (Mestrado em Ciências Agrárias) - Universidade Federal do Recôncavo da Bahia, Cruz das Almas, 2007. 